https://helda.helsinki.fi

\title{
A review of conversational practices in psychotherapy
}

\section{Vehviläinen, Sanna}

Cambridge University Press

2008

Vehviläinen , S , Peräkylä , A , Antaki , C \& Leudar , I 2008 , A review of conversational practices in psychotherapy . in E B A P E (ed.), Conversation analysis and psychotherapy . Cambridge University Press, Cambridge , pp. 188-197.

http://hdl.handle.net/10138/39210

publishedVersion

Downloaded from Helda, University of Helsinki institutional repository.

This is an electronic reprint of the original article.

This reprint may differ from the original in pagination and typographic detail.

Please cite the original version. 


\title{
11 A review of conversational practices in psychotherapy
}

\author{
Sanna Vehviläinen, Anssi Peräkylä, Charles Antaki, \\ and Ivan Leudar
}

The aim of this chapter is to present a systematic overview of some of the research results presented in this book. An overview like this cannot cover all that was important in the preceding chapters, but it will bring out something from each. We present the key results in Table 11.1. We then unpack the contents of the table, and, by setting them against earlier conversation analytic research on psychotherapy, set the contributions of this book in context.

In order to summarize the research findings in a meaningful way, we have had to choose one analytic dimension from which to consider them. We have chosen one that is the cornerstone of all conversation analytic research: sequence organization (see Schegloff, 2007). We have chosen, from the wealth of material in each chapter, to emphasize what we learn about the ways in which the utterances of one participant are linked to utterances of the other(s) in the interaction. The apparently simple conjunction of one person's utterance with another's is a site at which many therapy-relevant phenomena happen.

There are two distinctions that we have made in organizing the research results of the book on the basis of the conjunction of utterances. One is the distinction between initiatory and responsive actions. An initiatory action is one that calls for, or makes relevant, a response from the co-participants. Responsive action is, of course, such a response. As Schegloff (2007) amply demonstrates, the organization of talk-in-interaction is not exhausted by initiations and responses but is far more complex. Many actions that have been analysed in the chapters of this book are, in fact, both initiatory and responsive: they occupy the initiatory position with regard to one thing and are in a responsive position with regard to something else. However, for the purposes of this summary, we will stick to the basic differentiation between initiation and response.

The other distinction that has helped us to organize the material in the preceding chapters involves what therapy is about more directly, i.e. 
therapy as a particular kind of institutional interaction. It is a distinction between action, local consequence, and therapeutic function. Our basic unit of observation is action. Action is an initiative or responsive component of a sequence; or to put it in another (somewhat simplistic) way, it is an utterance that does (and is designed to do) some interactional work in relation to other utterances. "Questions" and "Answers" are paradigmatic examples of actions. Apart from such actions per se, however, the chapters of this book also describe what is accomplished in and through the actions. By local consequence, we refer to what a particular action brings about in its immediate environment: what the action does in this particular encounter, and how it changes the momentarily unfolding relation of the participants. Finally, by therapeutic function, we refer to the ways in which a particular action may contribute to, or resist, the overall objectives of a particular kind of psychotherapy; these objectives stretch throughout a therapeutic encounter and the entire therapy process. In sum: what we mean by action can be conceived as moving a piece in a chess game, while local consequence can be conceived as the move's contribution to the tactic, and therapeutic function as the move's contribution to the overall strategy.

\section{A survey of research findings}

The entries in Table 11.1 are generated from the work reported in this volume. The overall effect is bound to be somewhat miscellaneous and there are, clearly, significant gaps. Some of the gaps could be filled by referring to earlier CA work on psychotherapy (which is what we do later in this chapter) while many others are such that they require further research. CA work on therapy is still in its comparative infancy, and there is a great deal yet to be discovered.

A caveat: the entries in Table 11.1 ought not to be read as if they proceed, from left to right, i.e. from action through local consequences to therapeutic function, as automatic consequences which will be true in all cases. The local consequences of any action are contingent on what is going on in the environment that surrounds it. Thus, for example, Halonen's (Chapter 8) identification of questions employing zero-person and passive usage is only associated with the therapeutic function of "making clients admit they own a problem" in the specific circumstances of the usage she examines. Table 11.1, then, should best be seen as a listing of what features of talk have been studied (the left-hand column) and some cases of their local consequences in situ and their possible interpretations as therapeutic function. 
Table 11.1 Summary of the Research Results

1. Therapist's recipient actions

\begin{tabular}{|c|c|c|}
\hline Action & Some local consequences & Possible therapeutic function \\
\hline $\begin{array}{l}\text { LEXICAL } \\
\text { SUBSTITUTION } \\
\text { (Ch. } 4 \text { Rae) }\end{array}$ & $\begin{array}{l}\text { - intensifying emotion of } \\
\text { description } \\
\text { - showing attentiveness }\end{array}$ & $\begin{array}{l}\text { - encouraging the client to } \\
\text { talk more explicitly about } \\
\text { her feelings }\end{array}$ \\
\hline $\begin{array}{l}\text { EXTENSION } \\
\text { (Ch. } 6 \text { Peräkylä) }\end{array}$ & $\begin{array}{l}\text { - shaping client's talk } \\
\text { according to therapeutic } \\
\text { agenda } \\
\text { - showing the therapist's } \\
\text { access to what the patient } \\
\text { is describing }\end{array}$ & $\begin{array}{l}\text { - interpreting the } \\
\text { unconscious } \\
\text { - momentary meeting of } \\
\text { the participants' minds }\end{array}$ \\
\hline $\begin{array}{l}\text { FORMULATION } \\
\text { (Ch. } 2 \text { Antaki, Ch. } 3 \text { Bercelli } \\
\text { et al., Ch. } 4 \text { Rae, Ch. } 6 \\
\text { Peräkylä, Ch. } 7 \text { Vehviläinen) }\end{array}$ & $\begin{array}{l}\text { - "building a case" for } \\
\text { interpretation } \\
\text { - establishing facts } \\
\text { - guiding descriptions } \\
\text { towards the psychological } \\
\text { - managing the progress of } \\
\text { the therapy session }\end{array}$ & $\begin{array}{l}\text { - interpreting the } \\
\text { unconscious } \\
\text { - showing new perspectives } \\
\text { to client's life }\end{array}$ \\
\hline $\begin{array}{l}\text { REINTERPRETATIVE } \\
\text { STATEMENT } \\
\text { (Ch. } 3 \text { Bercelli } \text { et al., Ch. } 6 \\
\text { Peräkylä, Ch. } 7 \text { Vehviläinen, } \\
\text { Ch. } 9 \text { Leudar } \text { et al.) }\end{array}$ & $\begin{array}{l}\text { - presenting the therapist's } \\
\text { understandings of the } \\
\text { patient's talk and action } \\
\text { - topicalizing action; } \\
\text { confrontation }\end{array}$ & $\begin{array}{l}\text { - interpreting the } \\
\text { unconscious } \\
\text { - explicating the symbolic } \\
\text { meaning of the patient's } \\
\text { action } \\
\text { - identifying and managing } \\
\text { unconscious resistance }\end{array}$ \\
\hline
\end{tabular}

\section{Therapist's initiating actions}

\begin{tabular}{lcc} 
Action & Local consequence & Therapeutic function \\
\hline OPTIMISTIC & $\begin{array}{c}\text { presupposing optimistic } \\
\text { QUESTIONS }\end{array}$ & $\begin{array}{c}\text { enhancing the client's } \\
\text { agency }\end{array}$ \\
(Ch. 5 MacMartin) & client & \\
$\begin{array}{l}\text { FOLLOW-UP QUESTION } \\
\text { USING ZERO-PERSON }\end{array}$ & $\begin{array}{c}\text { regulating the applicability } \\
\text { of the narrative that is } \\
\text { (Ch. 8 Halonen) }\end{array}$ & $\begin{array}{c}\text { making clients admit their } \\
\text { problem }\end{array}$ \\
& beingtold & $\begin{array}{c}\text { making the identity of } \\
\text { addict constantly } \\
\end{array}$ \\
& & relevant to clients \\
\hline
\end{tabular}


Table 11.1 (cont.)

3. Client's responding activities

\begin{tabular}{|c|c|c|}
\hline Action & Local consequence & Therapeutic function \\
\hline $\begin{array}{l}\text { ANSWERS THAT RESIST } \\
\text { THE QUESTION } \\
\text { PRESUPPOSITIONS (Ch. } 5 \\
\text { MacMartin) }\end{array}$ & client resistance & - disavowing agency \\
\hline $\begin{array}{l}\text { DEFENSIVE RESPONSES } \\
\text { TO TOPICALIZATIONS } \\
\text { OF PRIOR ACTION } \\
\text { (Ch. } 7 \text { Vehviläinen) }\end{array}$ & client resistance & $\begin{array}{l}\text { - resisting treating one's } \\
\quad \text { own actions as a } \\
\text { psychoanalytical puzzle }\end{array}$ \\
\hline $\begin{array}{l}\text { ELABORATIONS } \\
\text { (Ch. } 6 \text { Peräkylä); } \\
\text { EXTENDED } \\
\text { AGREEMENTS (Ch. } 3 \\
\text { Bercelli et al.) }\end{array}$ & $\begin{array}{l}\text { response to (re)interpretation } \\
\text { that shows strongest uptake }\end{array}$ & $\begin{array}{l}\text { - showing one's perspectives } \\
\text { according to the } \\
\text { (re)interpretation } \\
\text { - becoming aware of } \\
\text { something previously } \\
\text { "unconscious" }\end{array}$ \\
\hline
\end{tabular}

\section{Therapists' recipient actions}

As Table 11.1 indicates, the studies reported in this book examine actions, the way particular actions are used in the interaction, and the role they play in carrying out particular therapeutic policies. Moreover, we can see that the majority of these actions are the therapist's recipient activities in which the clients' talk is in some particular way dealt with by the therapist. It is no coincidence that this has been the first focal point for comparison and accumulation of empirical knowledge in the CA study of therapeutic interaction. For one thing, at a general level, it has long been the case that CA studies of institutional talk have tended to focus on the talk of the institutional agent - be they doctor, teacher, emergency call-taker, news interviewer, or any other representative of an institution which brings off its work though repeated cycles of talk-based action. So the focus on the therapist, rather than the client, is in line with a general focus on the participant with identifiable service goals achieved by repeated routine conversational practices. As for the emphasis, within the therapists' practices, on how they deal with what their clients say, that is understandable as a reflection of psychotherapeutic expertise centring on the art of listening to, and interpreting, clients' talk. Another relevant feature of psychotherapeutic expertise which has to do with emotion - understanding, responding to, and in some particular way transforming the patient's emotion - is also prominently available for interactional examination in the recipient activities of therapists. 


\section{Lexical substitution}

This is the first recipient action in Table 11.1. In lexical substitution, the therapist offers alternative words for a just-prior expression produced by the client. Lexical substitution is a specific way of doing what in CA is called repair (dealing with problems of speaking, hearing, or understanding). There is an extensive literature of repair in ordinary conversation (e.g. Jefferson, 1987; Schegloff, Jefferson \& Sacks, 1977) and in some institutional environments (see e.g. Button, 1991; Moore \& Maynard, 2002), but Chapter 4 in this volume by Rae is the first contribution to the uses of repair in psychotherapeutic encounters. Rae suggests that this particular type of repair is used to serve specific purposes in psychotherapy: to encourage clients to show more explicitly their emotional involvement in what they are talking about .

\section{Extension}

This is the second type of recipient action in Table 11.1. In an extension, a speaker (the therapist) produces an utterance that is designed as syntactical continuation of the first speaker's talk. In earlier CA research, a particular type of extension (collaborative completion where one speaker completes a syntactical construction that the other has not (yet) completed) has been the subject of a number of studies (e.g. Sacks 1992b, 57-60; Lerner 1991). In therapeutic encounters, extension has been discussed by Ferrara (1994) and studied in more detail by Vehviläinen (2003a). The contributions to this book, alongside earlier research, show how therapists, by producing extensions, claim the availability of the topic for themselves, and through that also show that they have some access to the other speaker's experience. In her earlier study, Vehviläinen (2003a) showed how extensions are used in psychoanalysis to prepare the ground for an interpretation by shaping the clients talk in such a way that brings to the fore a "puzzle" (which is later on solved by interpretation). In this book, Peräkylä (Chapter 6) discusses cases where analyst extensions bring about moments when the participants' minds, as expressed in their talk, merge.

There is one important feature that is common to the use of extensions and repairs in psychotherapy. In the cases of the chapters in this book, the therapists are shown to claim knowledge of, and access to, their clients' experiences through their repairs and extensions, thereby stretching the boundaries of ownership of knowledge. In many other situations, speakers take care to orient to other speakers' experiences by indicating their limited access to that (Pomerantz, 1984; Peräkylä \& Silverman, 1991). In psychotherapies, we find moments when the therapist claims greater availability 
of the client's experience, for example through repairs and extensions. This kind of use of extensions and repairs may perform two quite different functions: confronting the client (i.e. showing or suggesting to the client that he or she does not fully recognize what is in his or her experience) or understanding the client (i.e. recognizing and validating the client's emotional experience).

\section{Formulation}

This is the next item in our table of therapists' recipient actions. Formulation has a rather long history as the target of CA studies on psychotherapeutic interaction (see e.g. Antaki, this volume; Antaki, Barnes \& Leudar, 2005; Davis, 1986; Hak \& de Boer, 1996). In the light of the earlier studies, formulation might appear as the "royal road into the practices of psychotherapy" (Antaki, Barnes \& Leudar, 2005, pp. 269-70): it has been considered to be the general category for the interpretive work that the therapist does with the client's talk. Certainly, in this book, formulation is prominently present, but the picture portrayed by the studies is more detailed and focused. The research presented in this book has specified the role of formulations in at least two ways. The sequential properties of formulations were specified by Antaki in Chapter 2 and by Bercelli et al. in Chapter 3 , by pointing out that rather than being any general descriptions of some aspect of the ongoing interaction, formulations in a specific way claim that they are saying what the other speaker said in his or her prior talk, and call for confirmation/disconfirmation of that understanding. At the same time, formulations involve selection and reshaping of the prior turn - and that is where therapeutic orientations come into the picture in a particular way. Besides their sequential properties, the local consequences of formulations were also specified in this book. Antaki (Chapter 2) outlined three kinds of work that formulations can do: they may (a) highlight some psychological state of affairs in the client's preceding talk and thus prepare for its further examination; (b) they may help the therapist to temporarily focus away from something and thereby to guide the progress of the interaction; or (c) they may serve as means for specifying diagnostically relevant facts.

\section{Reinterpretative statements}

We are also beginning to have a grasp of another type of therapist's turns, namely statement-designed turns that are constructed to explicitly exhibit the therapist's viewpoint. In Chapter 3, Bercelli, Rossano and Viaro discuss reinterpretative statements in cognitive and relational-systemic therapies. 
In such statements, the therapist reacts to the material provided by the client. But unlike formulations, which are designed to show that the speaker is resaying what the client said, reinterpretations are designed to present the therapist's own understandings concerning the client's experience. As pointed out by Bercelli et al., such reinterpretative statements are much like the interpretative statements found in psychoanalysis (Peräkylä, 2004a; 2005; Chapter 6 in this volume; Vehviläinen, 2003a) - in general, they are used to deliver to the client the results of the therapist's reasoning. In a similar vein, Leudar et al show in Chapter 9 how the therapists in Kleinian group therapy for children explicate in statement-formatted utterances what they take as the symbolic meaning of the children's play. Such statements in different types of therapies convey the therapist's view of the client's narration, mind, or action - the latter shown by Vehviläinen in Chapter 7 in the analyst's focus on the patient's prior action - and serve the therapeutic goal of challenging the patient's current understandings of his or her mind or action, and of offering new ones. As Vehviläinen shows, in psychoanalysis such challenges may function as prefaces to psychoanalytic interpretations, but also as an argumentative resource in the management of patient resistance and in pursuing interpretations. What is believed to be the significance of the new understanding that is proposed through statements varies according to the "school" of psychotherapy. In psychodynamic therapies, for example, these new understandings are thought to involve the expansion of the patient's conscious (as opposed to unconscious) experience, whereas in cognitive therapies, they might be thought of as involving more reality-oriented and functional ways of thinking.

\section{Therapists' initiating actions}

\section{Questioning}

Questioning is perhaps the most common type of initiating action in most institutional encounters (see e.g. Drew \& Heritage, 1992). In many settings (though not in all), questions are a vehicle for the professional's (rather than the client's) conduct. Earlier research on counselling interaction has explicated a number of sequential and turn design properties in questionanswer sequences that serve the therapeutic goals of family systems therapy (Peräkylä, 1995; Peräkylä \& Silverman, 1991). In this collection, therapists' questions figure especially in three papers. In Chapter 3 Bercelli et al., while not focusing their study on questions per se, nevertheless point out the importance of questions in cognitive and relational-systemic therapies. Therapists' questions are one of the recurrent turn types in such therapies; question-answer sequences produce materials which may be later on 
"reinterpreted" through the therapists' statements and the clients' responses to them.

Two specific kinds of questions are examined in more detail in this book. Interestingly, both question types seem to work towards ascribing the hearers' specific therapeutically relevant identities. In Chapter 5, MacMartin analyses questions with optimistic presuppositions in constructive psychotherapy. In particular, she focuses on wh-questions with presuppositions that affirm the client's "agency, competence, resilience, abilities, achievements, or some combination thereof" (p. XXX). As she points out, the local consequence of these questions is to ascribe positive features to the client, and thereby, they serve the therapeutic goal of enhancing the client's agency. In Chapter 8 Halonen, on the other hand, analyses the choice of person reference in Minnesota model group therapy for addicts, focusing especially on the uses, in Finnish, of the so-called zero-person construction and the passive mood. Her materials show examples of various actions among which questions are one. She shows how the zero- and passive-formatted questions allow the participants to talk in such a way that the experiences that are referred to get treated as general, something that anyone present can identify with. Thereby, these questions serve the therapeutic goal of helping the clients to accept the identity of an addict.

\section{Clients' responding actions}

Perhaps unusually in CA-inspired work on institutional interaction, but certainly not uniquely, we devote time in this book to the practices of the person on the other side of the service encounter: the client. The clients' responding actions are analysed in four chapters. Two of them (Chapter 3 by Bercelli et al. and Chapter 6 by Peräkylä) focus predominantly on responses that align with the therapist's initiatory action, whereas the other two (Chapter 5 by MacMartin and Chapter 7 by Vehviläinen) analyse misaligned responses. Bercelli et al. discuss three types of client responses to what they call therapists' reinterpretations (see above) in cognitive and relational-systemic therapies : acknowledgment tokens, mere agreements, and extended agreements. In an extended agreement, the client not only claims his or her agreement, but also accounts for that agreement through descriptions or narrations that corroborate the therapist's previous reinterpretation. An extended agreement in cognitive and relational-systemic therapies comes very close to what Peräkylä in Chapter 6 (and in 2005) calls patient's elaboration in response to the analyst's interpretation in psychoanalysis: in them, the patients take up some part of the interpretation and continue it, in the patient's own terms, and thereby show their acceptance and understanding of the interpretation. The parallel between cognitive 
and systemic therapies on one hand, and psychoanalysis on the other, is most interesting here and calls for further comparative research. In both kinds of therapies, these patient utterances seem to document the kind of uptake that the therapist is aiming at with his or her statement, which is formulated by Bercelli et al. as involving that the patients "display a change in perspective of their own events and experiences" (page XX).

Rather different patient responses were analyzed by MacMartin and Vehviläinen. MacMartin (Chapter 5) shows some of the ways in which the patients can resist the presuppositions of the therapists' optimistic questions in constructive psychotherapy. Such responses can involve, for example, downgrading the optimistic content of the question, focusing away from such contents, or joking about them. Also Vehviläinen, in Chapter 7, analyses patient resistance. She deals with actions that are taken by analysts as indications of patients' unconscious resistance, as well as the defensive responses to the analysts' confrontative focusings to the patients' prior actions.

\section{Clients' initiating actions}

This book offers accounts of different actions and related sequential patterns in psychotherapy, summarized in table 11.1. However, the table involves one very significant "blank spot". "Clients' initiations" are missing from it. Most psychotherapies are based on the client's narratives extended turns of talk on one's own experience. All the analyses of the therapist's recipient activities lean on the observations of the client's producing talk: either second-position responses to elicitations (Chapter 3 by Bercelli et al.) or first-position (spontaneous) tellings without the professional's opening initiation (as happens in psychoanalysis with so-called free association). It is perhaps symptomatic of the programme of the CA research on institutional interaction that, as we noted above, research first tends to turn towards the key activities of the professionals. However, the analysis of client's initiative actions - narratives or other types of systematic action - is necessarily one of the upcoming future research topics.

\section{One psychotherapy or many psychotherapies?}

Table 11.1 presents a number of actions and suggests what interactional local consequences these actions might serve, and what kind of therapeutic practices they might be part of. As pointed out in Chapter 1, conversation analytic research on psychotherapy is lagging far behind the level of systematic description that has been recently reached in CA research on medical consultations. Table 11.1 on page XXX is an effort towards systematization 
of the conversation analytical explication of psychotherapy. The research that the table seeks to encapsulate has identified and explicated a number of key actions. Further explication of these key psychotherapeutic actions (as well as the identification of others) is the task of future research.

However, one more question needs to be taken up. Unlike medical consultations which have rather uniform structure throughout the (Western) world, psychotherapy is divided into numerous approaches. Therefore, we need to ask to what degree the actions, local consequences and therapeutic functions summarized in Table 11.1 pertain to psychotherapy as whole, and to what degree they are related to specific kinds of therapy.

At the moment, no definite answer can be given. With the exception of Chapter 2 by Antaki, all chapters present data that comes from particular types of psychotherapy. In that sense, the results are, in most cases, specifically related to those therapy types. In some cases, the fact that the actions described are therapy-type specific is apparent also because those actions are closely related to the "stock of interactional knowledge" related to a specific type of therapy - for example, the optimistic questions analysed in Chapter 5 (MacMartin) arise from the theoretical ideas of constructivist therapies and might not be found in this form in other types of therapy.

On the other hand, there are some striking parallels between explications of different types of therapies: the ways in which formulations, therapist's statements and clients' responses to therapists' statements are organized in different types of therapies have much in common. For example, Bercelli et al. (Chapter 3) and Peräkylä (Chapter 6) describe clients' responses to therapists' (re)interpretative statements in quite complementary ways, even though their data come from two different therapeutic approaches (cognitive and relational-systemic therapies vs. psychoanalysis). Not much more, at the moment, can be said about the generalizability of the research results across different psychotherapeutic approaches. Future studies comparing different types of psychotherapies will tell us more. For the moment, however, the accumulating evidence from a variety of CA researchers around the world suggests that the application of CA methodology and theoretical insights will continue to find useful things to say about the practices of psychotherapists and their clients, and round out the sociological picture of one of the main institutions of mental-health culture in the West. 